\title{
Mogan Gölü (Ankara)'nde Sediment Taramasının Yüzey Sedimenti Besin Elementlerine Etkisinin Belirlenmesi
}

\author{
Determination of Influence of Sediment Dredging on Surface Sediment Nutrients \\ in Mogan Lake, Ankara
}

\begin{abstract}
ÖZET
Sediment tarama uygulamaları (uzaklaştırımı), göl içi yönetim girişimlerinden biridir. Mogan Gölü’nde sediment tarama sonrasi; a) Sediment kalite parametrelerinin (organik madde, toplam fosfor, toplam azot, toplam organik karbon ve redoks potansiyeli değeri) aylara ve istasyonlara bağlı değişiminin belirlenmesinin b) Sedimentin kirlenme durumunun, besin elementlerini baz alarak (kirlenme indeksi, zenginleşme faktörü, organik azot indeksi) ortaya konmasının amaçlandığı çalışmada, litoral bölgede iki istasyon (I. istasyon; özellikle maden işleme tesisleri ve evsel kaynaklı atık suların, II. istasyon; evsel atık ve tarımsal faaliyet kaynaklı atık suların ulaştığı alanda) seçilmiştir. Bulgulara göre; a) En yüksek toplam organik karbon (\%6.30mayıs ayında) ve toplam azot (\%0.69-kasım ayında) değeri II. istasyonda, toplam fosfor değeri mayıs ayında I. istasyonda (\%0.32) bulunmuştur. Gerek tarımsal gerekse evsel atık girişlerinin, her iki ayda ve istasyonda etkili olduğu belirlenmiştir. b) Kirlenme indeksi ve organik azot indeksleri, sedimentin en fazla azotla ve diğer besin elementlerine göre de önemli düzeyde kirlendiğine işaret etmektedir. Zenginleşme faktörüne göre en çok zenginleşme gösteren parametre ise toplam fosfor olarak belirlenmiştir. Kirlenme indeksleri, sedimentteki organik madde, toplam azot ve toplam fosfor düzeyleri üzerinde tarama girişiminin etkin olmadığını; tarama alanlarının önceliklendirilmesi, tarama derinliği, tekniği gibi konuların irdelenmesi gereğini ortaya
\end{abstract}

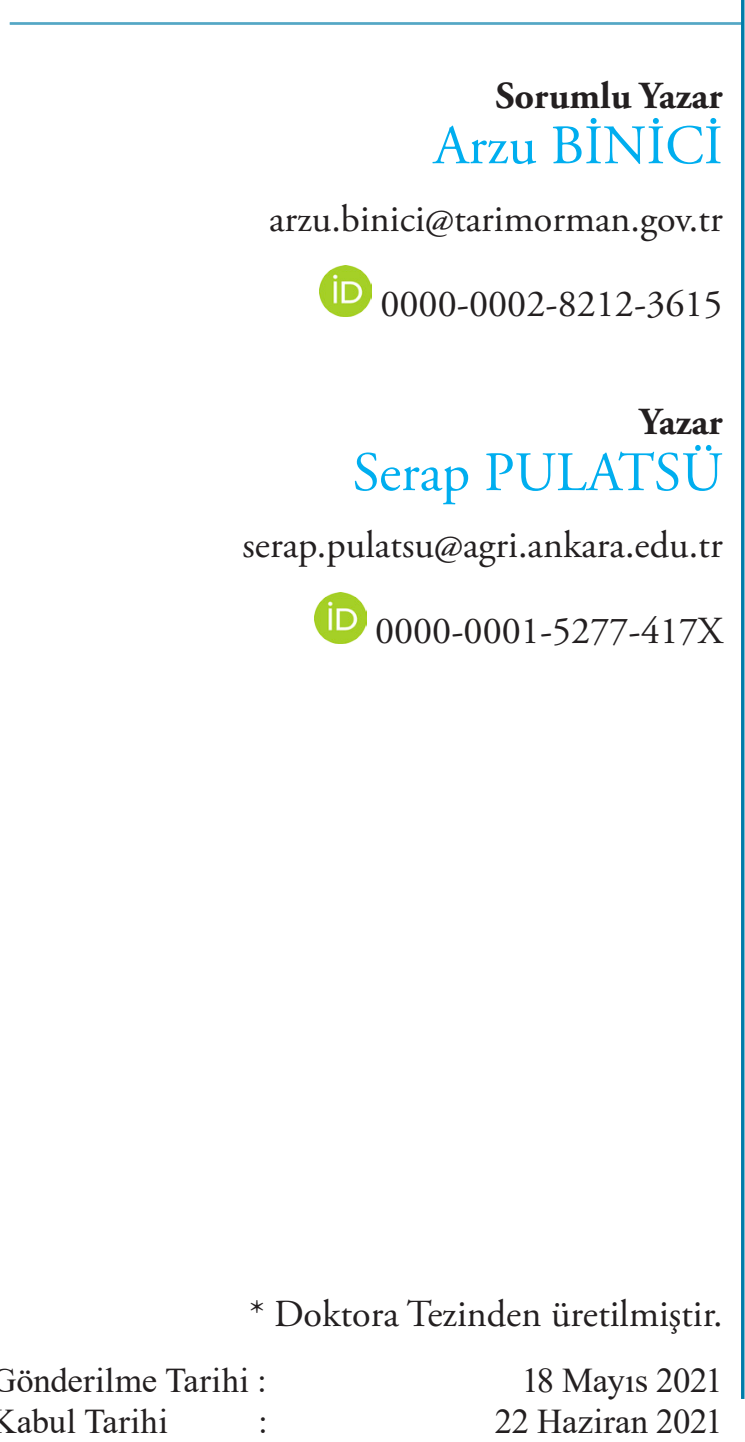


koymuştur. Ayrıca besin elementleri düzeyleri özellikle göl suyuna salınım riskleri nedeniyle izlenmelidir.

Anahtar Kelimeler: Sediment kalitesi, besin elementi, sediment tarama, kirlenme indeksi, Mogan Gölü

\section{ABSTRACT}

Sediment dredging practices (removal) is one of the intra-lake management initiatives. After sediment dredging in Lake Mogan; in the study aiming to determine a) The change of sediment quality parameters (organic matter, total phosphorus, total nitrogen, total organic carbon, redox potential) depending on the months-stations, b) The pollution status of the sediment, based on the nutrients (pollution index, enrichment factor, organic nitrogen index); two stations in the littoral zone (the station I; especially the mine processing facilities, domestic wastewater and the station II; the area where the domestic and agricultural wastewater reaches) were selected. According to the findings; a) The highest total organic carbon $(6.30 \%$ in May) and total nitrogen $(0.69 \%$ in November) values were found in the station II, and the total phosphorus value was found in the station I $(0.32 \%)$ in May. It was determined that both agricultural and domestic waste inputs are effective in both months-stations. b) Pollution index and organic nitrogen indexes indicate that the sediment is contaminated with the most nitrogen and other nutrients. According to the enrichment factor, the parameter showing the most enrichment was determined as total phosphorus. Pollution indexes have shown that the dredging attempts were not effective on organic matter, total nitrogen, and total phosphorus levels in the sediment; and in the context of reducing both the cost of dredging and the loss of time, the need to prioritize dredging areas, dredging depth, technique, timing etc. In addition, nutrient levels should be monitored, especially due to the risks of release into lake water.

Key Words: Sediment quality, nutrient, sediment dredging, pollution index, Mogan Lake

\section{GİRIŞ}

Sediment tarama uygulamaları, dipteki besin maddesi yönünden zengin taban çökeltileri olarak isimlendirilen sedimentleri uzaklaştırmak olarak tanımlanabilecek göl içi yönetim girişimlerinden biridir (Pulatsü vd. 2015). Bu uygulamanın; sedimentten geçici olarak besin elementleritoksik madde salınımı, fitoplankton verimliliğinde artış, koku sorunu, bentik balıkların besinini oluşturan organizmalardaki geçici azalma, sedimenti barındıran boşaltım sahasının çevresel etkisi gibi dezavantajları söz konusudur (Peterson 2007).

Sediment tarama uygulamalarının sığ-ötrofik göllerde iç kaynaklı besin elementi yükünün azaltılmasında etkili olduğu (Zhang vd. 2010), ancak sediment tarama derinliğinin, sedimentten kaynaklanan iç kaynaklı besin elementi yükü veya makrofit büyümesinin kontrolüne yönelik derinleştirme girişimlerinde dikkate alınması gereken bir konu olduğu belirtilmiştir (Welch ve Jacoby 2004). Ayrıca sediment tarama sonuçlarının, besin elementleri üzerindeki etkilerinin değerlendirilmesi uzun bir süreye ihtiyaç göstermektedir. Bu konuda yapılan çalışmalar, 2-5 yıllık bir süreci kapsamaktadır (Ryding vd. 2006, Wang ve Feng 2007).

Gölbaşı Özel Çevre Koruma Bölgesi'nde bulunan ve Ankara’ya yakınlığı nedeniyle rekreasyonel açıdan önem taşıyan Mogan Gölü’nün çevresi konut, sanayi, turizm gibi farklı faaliyetlere ev sahipliği yapmaktadır. Yoğun bir kentsel-endüstriyel kirlilik baskısı altında bulunan ötrofiksığ gölde, bazı göl yönetim uygulamaları uzun yıllardır süregelmiştir. Özellikle sediment tarama (dredging) girişimi, Mogan Gölü’nde zaman zaman gerçekleştirilmektedir.

Mogan Gölü’nde, Temmuz 2004-Haziran 2005 tarihleri arasında fosfor salınımı tahmin edilmiş, dış kaynaklı fosfor yükünün azaltılmasını takiben, düşük düzeyde tahmin edilen ve sedimentten fosfor salınımı ile karakterize edilen iç kaynaklı fosfor yükünün etkin hale geçebileceği belirtilmiştir (Topçu ve Pulatsü 2008). 2006 yılından itibaren gölde yerel yönetim tarafından öncelikli olarak dip sedimenti temizleme çalışmalarını kapsayan bazı göl yönetim uygulamaları yürütülmüş; Topçu ve Pulatsü (2017) tarafından ise sedimente ilişkin fosfor salınım değerleri (0.1754-1.1249 mg/m2.gün) dikkate alındığında mevcut yönetim uygulamalarına şu an için ihtiyaç olmadığı bildirilmiştir. Topçu vd. (2018), Mogan 
Gölü'nde yürütttükleri son çalışmada da sediment üstü sudaki çözünmüş fosfat değeri ekim ayında $0.008 \mathrm{mg} /$ L'nin, temmuz ayında $0.046 \mathrm{mg} /$ L'nin altına düştüğünde sedimentten göl suyuna olabilecek fosfor salınım riskine işaret etmişlerdir.

Bu çalışma ile Mogan Gölü’nün rekreaktif değerinin artırılmasına yönelik bir göl yönetim uygulaması olan sediment tarama (uzaklaştırımı) ertesi; a) Sediment kalite parametrelerinin (organik madde, toplam fosfor, toplam azot, toplam organik karbon ve redoks potansiyeli değeri) belirlenmesi b) Sedimentin kirlenme durumunun, besin elementlerini baz alarak (kirlenme indeksi, zenginleşme faktörü, organik azot indeksi) ortaya konması amaçlanmıştır. Araştırma bulguları ile gölde sediment tarama uygulamaları ertesi, sediment kalitesinin ortaya konacak olmasının, sedimentteki olası değişimlere ve girişimin etkinliğine ışık tutacağı düşünülmektedir.

\section{MATERYAL ve YÖNTEM}

\section{Araştırma Alanı}

Araştırma alanı olan Mogan Gölü, Ankara Çayı Alt Havzası'nda ve Ankara'nın $20 \mathrm{~km}$ güneyinde Ankara-
Konya yolu üzerinde yer alan, büyük oranda yağış ve irili ufaklı beşten fazla dereden gelen sularla beslenen alüvyal set gölüdür. Normal su kotu 972 m, normal su kotunda göl alanı $664 \mathrm{~km}^{2}$, göl ortalama derinliği 3-5 m ve normal su seviyesinde göl hacmi 13.34 milyon m³'tür. Mogan Gölü yeraltı suyu beslemesi oldukça düşük olup, su girdisi yazları genelde kuruyan düzensiz rejimli dereler vasıtasıyla olmaktadır (Anonim 2016).

Mogan Gölü litoral bölgede, tabanı sediment örneklerinin alımına uygun olan ve gölü kirleten kaynakları da temsil edecek şekilde iki istasyon seçilmiştir. I. istasyon; özellikle maden işleme tesisleri ve evsel kaynaklı atık suların ulaştığı alanda, II. İstasyon; evsel atık ve tarımsal faaliyet kaynaklı atık suların ulaştı̆̆ı alanda belirlenmiştir. Araştırma alanı ve istasyonların konumu Şekil 1'de sunulmuştur.

\section{Yöntem}

Mogan Gölü’nde litoral bölgede belirlenen istasyonlardan 2020 yılının Mayıs ve Kasım aylarında olmak üzere iki farklı periyotta yüzey sediment örnekleri alınmıştır.

Sediment alma kepçesiyle alınan örnekler, koyu

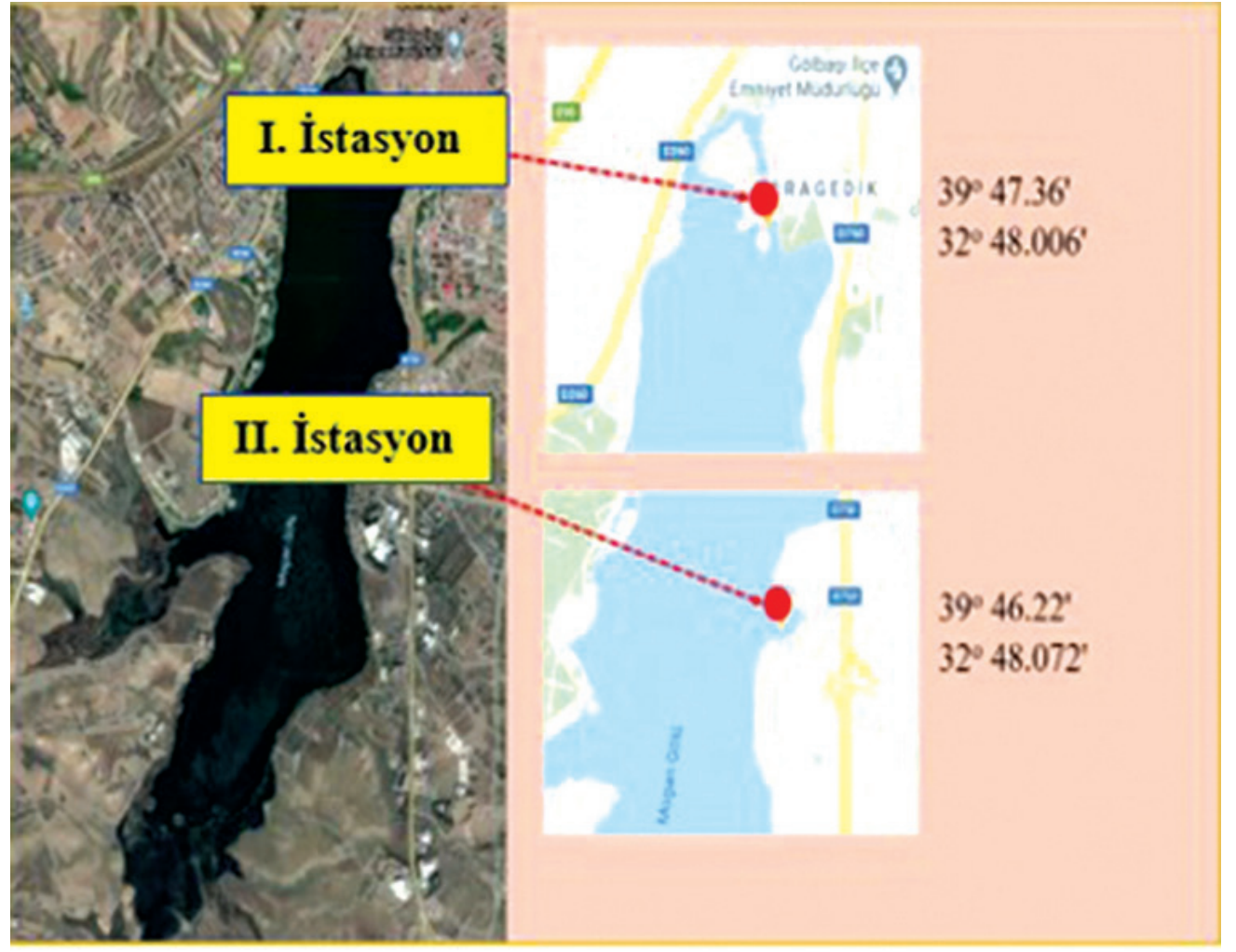

Şekil 1. Araştırma alanı ve istasyonların konumu renkli naylon torbalarda ve soğuk ortamda laboratuvara ulaştırılmıştır. Sediment örneklerinde redoks potansiyeli (ORP ölçümü) değerleri taşınabilir pH/ORP ölçer ile sahada belirlenmiştir.

Sediment Örneklerinde Ölçüm ve Analizler:

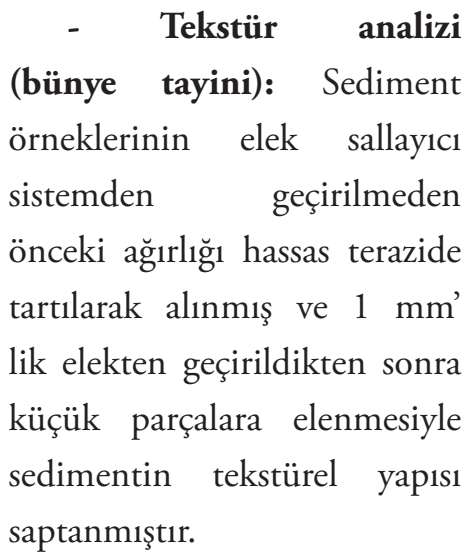


- Organik madde tayini (OM, \%): Sediment örneklerine kuru yakma metoduna göre kül firınında $550^{\circ} \mathrm{C}$ de 2 saat yakılma işlemi uygulanmış bu işlemde yakılmadan önceki ve sonraki tartım ağırlıkları kaybı dikkate alınmıştır (Kacar 1995).

- Toplam organik karbon (TOK, \%): Elementer analiz cihazı ile Dumas metodu ile belirlenmiştir.

- Toplam azot (TA, \%): Elementer analiz cihazı ile Dumas metodu ile belirlenmiștir.

-Toplam fosfor tayini (TF, \%): Vanadomolibdofosforik sarı renk metodu ile Kacar ve İnal (2008)'e göre yapılmıştır.

\section{Sedimentteki Besin Elementlerine İlişkin Indeksler:}

\section{-Kirlenme indeksi}

Kirlenme indeksi (Ki), Zhang vd. (2015)'e göre belirlenmiştir.

$\mathrm{K}_{\mathrm{i}}=\mathrm{C}_{\mathrm{i}} / \mathrm{C}_{0 \mathrm{i}}$

$\mathrm{C}_{\mathrm{i}}$ : Sedimentteki besin elementi konsantrasyonu

$\mathrm{C}_{0 \mathrm{i}}$ : Çevresel ölçüm standart değerleri (OM (\%): 1.724, TA (\%): 0.055 , TF (\%): 0.06)

\section{-Organik indeks ve organik azot indeksi}

Organik indeks = Organik karbon (\%) x Organik azot (\%)

Organik azot indeksi $=\mathrm{TN}(\%) \times 0,95$

Çizelge 1. Sedimentte organik indeksi (\%) değerlendirme standartları (Zhang vd. 2015)

\begin{tabular}{|c|c|c|c|c|}
\hline $\begin{array}{c}\text { Organik } \\
\text { indeks }\end{array}$ & $<0,05$ & $0,05-0,35$ & $0,35-0,75$ & $\geq 0,75$ \\
\hline $\begin{array}{c}\text { Organik } \\
\text { azot }\end{array}$ & $<0,033$ & $0,033-0,066$ & $0,066-0,239$ & $>0,239$ \\
\hline $\begin{array}{c}\text { Kalite } \\
\text { türü }\end{array}$ & Kirlenmemiş & Az kirlenmiş & Kirlenmiş & $\begin{array}{c}\text { Çok } \\
\text { kirlenmiş }\end{array}$ \\
\hline Sınıf & I & II & III & IV \\
\hline
\end{tabular}

\section{- Zenginleşme faktörü}

Zenginleşme faktörü ( $\left.\mathrm{ZF}_{\mathrm{i}}\right)$, Zhang vd. (2015)'e göre belirlenmiştir.

$\mathrm{ZF}_{\mathrm{i}}=\mathrm{C}_{\mathrm{i}} / \mathrm{CBV}$

$\mathrm{C}_{\mathrm{i}}$ : Sedimentteki besin elementi konsantrasyonu

CBV: Sedimente ilişkin geçmiş besin elementi konsantrasyonu verileri (Pulatsü vd. (2008), Topçu ve Pulatsü (2017) tarafindan bildirilen TF, TA ve TOK'a ilişkin değerlerin ortalaması esas alınmıştır).

Zenginleşme faktörüne göre sınıflandırmada ise, Sasikala vd. (2009) tarafından belirtilen değerler esas alınmıştır. $\mathrm{Bu}$ değerlere göre; $\mathrm{ZF}<1$ : zenginleşme yok, $\mathrm{ZF}=1-3$ : az seviyede zenginleşme, $\mathrm{ZF}=3-5$ :orta seviyede zenginleşme, $\mathrm{ZF}=5$-10:orta seviyeden daha yüksek seviyede zenginleşme, $Z \mathrm{ZF}=10-25$ :yüksek seviyede zenginleşme, $\mathrm{ZF}=25-50$ :çok yüksek zenginleşme, $\mathrm{ZF}>50$ :aşırı seviyede zenginleşmeyi ifade etmektedir.

\section{Istatistiki Analizler}

Değişkenlerin farklıistasyonlaragörekarşılaştırılmasında Mann-Whitney testi, aynı istasyonlardaki aylara göre karşılaştırılmasında ise Wilcoxon işaretli sıra sayıları testi kullanılmıştır (Çolak 2021). İstatistiksel analizler için SPSS 23 yazılımlarından yararlanılmıştır.

\section{BULGULAR}

Sediment örneklerine ait tekstür analizi (bünye tayini) sonuçlarına göre sediment örneklerinde her iki ay ve istasyonda sedimetin kil oranı silte göre oldukça yüksek saptanmış, kuma rastlanmamıştır. I. istasyonda mayıs ve kasım ayında kil-silt değerleri (\%) sırasıyla; 82,82-17,18 ve 87,13-12,86 iken, II. istasyonda mayıs ve kasım ayındaki kil-silt değerleri (\%) sırasıyla; 55,55-44,44 ve 54,86-45,13 olarak bulunmuştur.

Sediment örneklerine ait organik madde, toplam organik karbon, toplam azot, toplam fosfor analizine ve redoks potansiyeli ölçümlerine ilişkin bulgular Çizelge 2'de sunulmuștur. 
Çizelge 2. İstasyon ve aylara bağlı ortalama organik madde (OM, $\mathrm{N}=4$ ), toplam organik karbon (TOK), toplam azot (TA), toplam fosfor (TF, N=2) ve redoks potansiyeli $(\mathrm{mV}, \mathrm{N}=4) \quad$ değerleri

\begin{tabular}{|c|c|c|c|}
\hline \multirow{2}{*}{ Parametreler } & \multirow{2}{*}{ Aylar } & \multicolumn{2}{|c|}{ İstasyonlar } \\
\cline { 3 - 4 } & Mayıs & $6,15 \pm 0,46^{\mathrm{a}^{*} \mathrm{~A}^{* *}}$ & $4,59 \pm 0,37^{\mathrm{bB}}$ \\
\hline \multirow{2}{*}{ OM (\%) } & Kasım & $11,04 \pm 0,24^{\mathrm{cA}}$ & $19,83 \pm 5,73^{\mathrm{dB}}$ \\
\cline { 2 - 4 } & Mayıs & $0,88 \pm 0,67$ & $1,94 \pm 1,25$ \\
\hline \multirow{2}{*}{ TOK (\%) } & Kasım & $<0,1$ & $6,30 \pm 1,12$ \\
\cline { 2 - 4 } & Mayıs & $0,46 \pm 0,44$ & $0,70 \pm 0,70$ \\
\cline { 2 - 4 } & Kasim & $<0,1$ & $0,59 \pm 0,02$ \\
\hline \multirow{2}{*}{ TF (\%) } & Mayıs & $0,07 \pm 0,02$ & $0,16 \pm 0,15$ \\
\cline { 2 - 4 } & Kasım & $0,32 \pm 0,10$ & $0,27 \pm 0,04$ \\
\hline \multirow{2}{*}{$\begin{array}{c}\text { Redoks pot. } \\
(\mathrm{mV})\end{array}$} & Mayıs & $-34,25 \pm 0,96^{\mathrm{aA}}$ & $-9,5 \pm 1,29^{\mathrm{bB}}$ \\
\cline { 2 - 4 } & Kasım & $-15,5 \pm 1,29^{\mathrm{cA}}$ & $-50,5 \pm 1,29^{\mathrm{dB}}$ \\
\hline
\end{tabular}

*Aynı satırdaki küçük harfler, aynı ayda her bir parametrenin istasyonlar arası farklılı̆̆ını,

"Aynı sütundaki büyük harfler ise aynı istasyonda her bir parametrenin aylar arası farklıllğını göstermektedir.

Çizelge 2'de görüleceği üzere, organik maddeye ilişkin ortalama değerler istasyonlar arasında istatistiki açıdan anlamlı bir farklılık gösterirken ( $\mathrm{p}<0.05$ ), aylar arası farklılı istatistiki olarak önemsiz bulunmuştur.

Toplam organik karbon ve toplam azot verileri esas alındığında II. istasyon değerleri, I. istasyona göre daha yüksek tespit edilmiştir. En yüksek ortalama toplam organik karbon değeri $(6.30 \pm 1,12)$ ve toplam azot değeri $(0.59 \pm 0,02)$ kasım ayında II. istasyonda belirlenmiştir Mogan Gölü’nde sedimente ilişkin yüksek redoks potansiyeli değeri, I. istasyonda mayıs ayında II. istasyonda ise kasım ayında ölçülmüştür. Bu parametre bakımından her iki ay için istasyonlar arası farklılık istatistiki açıdan önemli $(\mathrm{p}<0.05)$, her iki istasyonun mayıs ve kasım ayları ölçüm değerleri arasındaki farklılık ise önemsiz seviyede bulunmuştur (Çizelge 2). Sedimentteki besin elementleri ile kirlenmeye ilişkin sonuçlar ise Çizelge 3'de sunulmuştur.
Çizelge 3. Sedimentte kirlenme indeksi $\left(\mathrm{K}_{\mathrm{i}}\right)$, organik indeks, organik azot indeksi ve zenginleşme faktörü (ZF) değerleri

\begin{tabular}{|c|c|c|c|}
\hline \multirow{2}{*}{$\begin{array}{c}\text { Kirlenme } \\
\text { parametreleri }\end{array}$} & \multirow[b]{2}{*}{ Aylar } & \multicolumn{2}{|c|}{ İstasyonlar } \\
\hline & & I & II \\
\hline \multirow{2}{*}{ Kİ-OM } & Mayıs & 3,56 & 6,43 \\
\hline & Kasım & 2,65 & 9,89 \\
\hline \multirow{2}{*}{ Kİ-TF } & Mayıs & 1,17 & 2,67 \\
\hline & Kasım & 5,33 & 4,50 \\
\hline \multirow{2}{*}{ Kİ-TA } & Mayıs & 8,36 & 12,54 \\
\hline & Kasım & - & 10,73 \\
\hline \multirow{2}{*}{$\begin{array}{l}\text { Organik } \\
\text { indeks }\end{array}$} & Mayıs & 0,40 & 1,34 \\
\hline & Kasım & - & 3,72 \\
\hline \multirow{2}{*}{$\begin{array}{c}\text { Organik azot } \\
\text { indeksi }\end{array}$} & Mayıs & 0,44 & 0,67 \\
\hline & Mayıs & - & 0,56 \\
\hline TF-ZF* & \multicolumn{3}{|c|}{3,56} \\
\hline TF-ZF** & \multicolumn{3}{|c|}{2,52} \\
\hline TA-ZF** & \multicolumn{3}{|c|}{1,21} \\
\hline TOK-ZF** & \multicolumn{3}{|c|}{0,44} \\
\hline
\end{tabular}

ZF*: Pulatsü vd (2008), ZF**: Topçu ve Pulatsü (2017)'nin bildirdiği değerler kullanılmıştır.

$\mathrm{ZF}<1$ : zenginleşme yok, $\mathrm{ZF}=1-3$ : az seviyede zenginleşme, $\mathrm{ZF}=3-5$ : orta seviyede zenginleşme, $\mathrm{ZF}=5-10$ : orta seviyeden daha yüksek seviyede zenginleşme, $Z F=10-25$ : yüksek seviyede zenginleşme, $\mathrm{ZF}=25-50$ : çok yüksek zenginleşme, $\mathrm{ZF}>50$ :aşırı seviyede zenginleşme (Sasikala vd. (2009))

Sediment örneklerinde organik madde için kirlenme indeksi değerleri kasım ayında II. istasyonda daha yüksek iken, TF için yine kasım ayında olmak üzere I. istasyonda daha yüksek bulunmuştur. Toplam azot için en yüksek değer II. istasyonda (\%12.54) bulunmuştur. Çizelge 3'de verilen bulgular ışığında, en yüksek değer toplam azota ait olduğu için Sedimentin besin elementleri açısından en fazla azot ile kirlendiği söylenebilir.

Sediment örneklerinde gerek organik indeks gerekse organik azot indeks sonuçları, II. istasyonda her iki ayda I. 
istasyona göre daha yüksek saptanmıştır (Çizelge 3). Bu iki parametre açısından mayıs ayı verileri, kirlenmiş-III. sınıfa (I. istasyon hariç), her iki ayda ise II. istasyon çok kirlenmiş seviyeyi gösteren IV. sınıfa işaret etmektedir. Gerek kirlenme indeksi gerekse azot ile ilintili bu iki parametre sonuçları, sedimentin genel anlamda azot ile önemli ölçüde kirlendiğini desteklemektedir.

Zenginleşme faktörü açısından TF için Pulatsü vd. (2008)'in çalışmasına ilişkin sonuçlar esas alındığında orta düzeyde bir zenginleşme ( $\mathrm{ZF}=3-5)$ söz konusudur. Topçu ve Pulatsü (2017)'nin bildirdiği verilere göre ise toplam fosfor ve toplam azot değerleri bakımından az düzeyde bir zenginleşmeden $(\mathrm{ZF}=1-3)$ söz edilebilir. Yine Topçu ve Pulatsü (2017)'nin bildirdiği değerler baz alındığında, toplam organik karbon bakımından zenginleşme olmadığı $(\mathrm{ZF}<1)$ saptanmıştır. Bu bağlamda, geriye dönük toplam fosfora ait en eski veriyi kapsayan Pulatsü vd. (2008)'e ait bulgular ışığında, en çok zenginleşme gösterdiği tespit edilen parametre toplam fosfor olarak belirlenmiştir (Çizelge 3).

\section{TARTIŞMA ve SONUÇ}

Göllerin iyileştirilmesi amacıyla, göl tabanından sedimentin uzaklaştırılması işlemi olan sediment (dip) tarama uygulaması, ötrofikasyonu önleme çarelerinden biridir. Bu uygulama, Mogan Gölü’nde de gölün rekreatif devamlılığı açısından zaman zaman yapılmaktadır.

Göllerde sedimentteki azot düzeylerinin mevsimsel farklılıklar gösterdiği farklı çalışmalarla ortaya konmuştur. Liao ve Lean (1978) tarafından, tabakalaşmamış ve oksijenli sığ bir göl olan Ontario Gölü’nde sedimentin \% 1,5 gibi oldukça yüksek düzeyde toplam azot içerdiğini, göl sedimentinde kış mevsiminde belirlenen toplam azot yüzdelerinin yazın saptanan değerden daha düşük olduğunu belirtmişlerdir. Carignan (1985), sedimentte toplam azot düzeyinin makrofit ölümü ile kışın maksimum düzeye ulaştığını, baharda daha düşük bulunduğunu bildirmiştir. Jonsson (1997), bahar döneminde saptanan toplam azot değerinin (\%40) yaz dönemine (\%79) göre daha düşük olduğunu, Lau (2000) ise, sedimentte azot düzeyinin nisanağustos aylarında maksimum düzeye ulaştığını belirtmiştir. Xu vd. (2003) tarafından ötrofik bir gölde yürütülen çalışmada ise, sedimentteki toplam fosfor değerinin 487-
$551 \mu \mathrm{g} / \mathrm{gKA}$ olduğu, bahar aylarındaki maksimum değerin, göle ulaşan yoğun silt ve besin elementi girdisinden kaynaklandığı bildirilmiştir.

Mogan Gölü'nde yürütülen bu araştırmada, sedimentteki toplam azot değerleri, her iki ayda da I. istasyonda, II. istasyona göre daha düşük bulunmuştur. Mayıs ayı toplam azot değerleri kasım ayına göre daha yüksek saptanmış olup, yukarıdaki bildirişlerin bir bölümü ile benzerlik göstermekte; sedimentteki toplam azot miktarının baharda özellikle tarımsal faaliyet kaynaklı kirleticiler başta olmak üzere yüzeysel akışlarla göle ulaşan girdilerdeki artışla ilintili olabileceği düşünülmektedir. Sedimente ilişkin toplam fosfor değerleri ise, toplam azotun aksine kasım ayında ve I. istasyonda maksimuma (\%32) ulaşmıştır.

Çalışma kapsamında Mogan Gölü sedimentine ilişkin organik madde seviyeleri (\%4.56-\%17.05), aynı göl için Pulatsü vd. (2008) tarafından belirtilen verilere (\%3.30\%5.42) göre daha yüksek tespit edilmiştir. Araştırma dönemlerinin farklılığı dikkate alındığında, güncel organik madde düzeyleri bir miktar zenginleşmeye işaret etmektedir. Sedimentteki organik madde seviyesinde tespit edilen yaklaşık üç katlık bir artış, göldeki sediment tarama faaliyetinin sedimentin organik madde düzeyi üzerinde de önemli ölçüde olumlu bir etkisi olmadığını desteklemektedir

Mogan Gölü'nde sedimentin TOK konsantrasyonu I. istasyonda oldukça düşük seviyelerde seyrederken, II. istasyonda kasım ayında maksimum olan $63000 \mu \mathrm{g} / \mathrm{g}$ KA değerine ulaşmıştır. Belirlenen maksimum değerin bile Topçu ve Pulatsü (2017)'nin aynı göl sedimenti için belirttikleri maksimum seviyeden $(79675 \mu \mathrm{g} / \mathrm{g}$ KA) daha düşük olması, bu parametre bakımından sediment tarama girişiminin belirli düzeyde de olsa indirgenme yönünde etki ettiği şeklinde yorumlanabilir.

Yılgör vd. (2012) tarafından, Bafa Gölü (Batı Anadolu) dip sediment örneklerinde \%0.35 ve \%3.58 arasında değişim gösterdiği bildirilen toplam organik karbon konsantrasyonları, Mogan Gölüyüzeysedimentörneklerinde daha yüksek düzeylerde (\%0.88-\%6.30) değişim göstermiş, toplam inorganik karbon konsantrasyonunun derinliğe 
bağlı değişimi bu çalışma kapsamında dikkate alınmamıştır.

Topçu ve Pulatsü (2017), Mogan Gölü sedimenti için TA değişim aralığını 3250,0 $\mu \mathrm{g} / \mathrm{g}$ KA- 6325,0 $\mu \mathrm{g} / \mathrm{g}$ KA olarak tespit etmişlerdir. Bu çalışmada ise, I. istasyonda düşük seviyelerde ve kasım ayında belirlenen TA değeri, aynı ayda II. istasyonda $6900 \mu \mathrm{g} / \mathrm{g}$ KA değerine ulaşarak daha yüksek bulunmuştur. Dolayısı ile kasım ayı-I. istasyon hariç olmak üzere bu çalışmada belirlenen sediment toplam azot değerleri, Mogan Gölü'nde Nisan 2015-Ocak 2016'da mevsimlik olarak alınan sediment örneklerindeki toplam azot değerlerinden (Topçu ve Pulatsü 2017) daha yüksek seviyelerde seyretmiştir. Bu durum Wang ve Feng (2007)'nin bulgularını destekleyerek, toplam azot değeri üzerinde tarama girişiminin etkin olmadığı şeklinde yorumlanabilir.

Mogan Gölü sedimentinde TF konsantrasyonu baz alındığında, Topçu ve Pulatsü $(2008,2017)$ tarafindan bildirilen konsantrasyon değişim aralığı sırasıyla; 286,0 $\mu \mathrm{g} / \mathrm{g}$ KA- $892,250 \mu \mathrm{g} / \mathrm{g}$ KA ve $620,0 \mu \mathrm{g} / \mathrm{g}$ KA- 1047,50 $\mu \mathrm{g} / \mathrm{g}$ KA iken bu çalışmada; 700-3200 $\mu \mathrm{g} / \mathrm{g}$ KA arasında değişim göstermiştir. $\mathrm{Bu}$ durum, sediment tarama girişiminin bu parametre açısından da çok etkin olmadığı şeklinde yorumlananabilir. Bulgularımız, Wang ve Feng (2007) tarafından South Gölü'nde (Çin) sediment tarama uygulamalarının, toplam fosfor değerlerinin azaltılmasında etkili olduğunu bildirdiği çalışma sonuçları ile örtüşmemektedir.

Araştırmamızda OM/TA oranı ortalama 19,43 saptanmış olup, Zhang vd. (2015) tarafından, sedimentin OM/TA oranı 10'dan büyük ise, sedimentteki organik maddenin temel olarak dış kaynaklı olabileceğine ilişkin bildirişi ile uyum göstermektedir.

Sonuç olarak, çalışma kapsamında gerek sedimentte belirlenen organik madde, toplam azot, toplam fosfor düzeyleri gerekse toplam azot ve toplam fosfora ilişkin kirlenme indeks sonuçları tarama girişiminin önemli ölçüde etkin olmadığı yönündedir. Tarama uygulamalarının maliyeti, çevresel etkileri, süreci vb. unsurlar bağlamında, Mogan Gölü için de zamanlama, tarama alanlarının önceliklendirilmesi, tarama derinliği, tekniği gibi konuların ele alınması gerektiği düşünülmektedir. Ayrıca göl havzasındaki antropojenik kirleticiler devam ettikçe, gölün sürdürülebilir kullanımı açısından sedimentin besin elementi düzeylerinin rutin olarak izlenmesi uygun olacaktır. Zira ötrofikasyonu tetikleyen ve sedimentte biriken besin elementlerinin, $\mathrm{pH}$, redoks potansiyeli, sıcaklık ve organik madde gibi bazı unsurlardaki değişikliklere bağlı olarak göl suyuna salınabileceği riski göz ardı edilmemelidir.

\section{TEŞEKKÜR}

$\mathrm{Bu}$ projenin (19L0447010) gerçekleştirilmesi için gerekli mali desteği sağlayan Ankara Üniversitesi Bilimsel Araştırma Projeleri Koordinatörlüğü’ne şükranlarımızı sunariz.

\section{KAYNAKLAR}

Anonim. 2016. T.C. Orman ve Su İşleri Bakanlığı, Su Yönetimi Genel Müdürlüğü. Göller ve Sulak Alanlar Eylem Planı, 2016-2018, 27-30 s., Ankara.

Carignan, R. 1985. Nutrient dynamics in a littoral sediment colonized by the submersed macrophyte Myriophyllum spicatum. Can. J. Fish. Aquat. Sci., 42, 1303-1311.

Çolak, E. 2021. Mann-Whitney U ve Wilcoxon T testleri. https://eczacilik.anadolu.edu.tr/bolumSayfalari/ belgeler/ecz2014\%2010_20140512122216.pdf. Erişim tarihi: 6.06.2021.

Jonsson, A. 1997. Fe and Al sedimentation and their importance as carriers for $\mathrm{P}, \mathrm{N}$ and $\mathrm{C}$ in a large humic lake in Northern Sweden. Water, Air and Soil Pollution, 99, 283-295.

Kacar, B. 1995. Bitki ve toprağın kimyasal analizleri. Toprak Analizleri. Ankara Üniversitesi Ziraat Fakültesi Eğitim Araştırma ve Geliştirme Vakfı Yayınları, 3, 705 s.

Kacar, B. ve İnal, A. 2008. Bitki analizleri. Ankara Nobel Yayın Dağıtım, 978 (605), 395-036-3.

Lau, S., S. 2000. The signifigance of temporal variability in sediment quality for contamination assessment in a coastal wetland. Water Res., 34 (2), 387-394.

Liao, C, F, H. and Lean, D., R., S. 1978. Seasonal changes in nitrogen compartments of lakes under different loading conditions. J. of Fish. Res. Board Can., 35, 1095-1101. 
Peterson, S., A. 2007. Lake restoration by sediment removal. Journal of the American Water Resources Association. 18:3-423-436.

Pulatsü, S., Topçu A., Kırkağaç, M., Köksal, G. 2008. Sediment phosphorus characteristics in the clearwater state of Lake Mogan, Turkey. Lakes \& Reservoirs: Research and Management, 13, 197-205.

Pulatsü, S., Topçu, A., Yılmaz, E. 2015. Göllerde Ötrofikasyonun Kontrolü: Sediment Tarama Uygulamaları. Iğdır Univ. J. Inst. Sci. \& Tech, 5, 1, 51 56.

Ryding, S. O. 2006. Lake trehörningen restoration project. Changes in water quality after sediment dredging. Hydrobiologia, 91, 92, 549-558.

Topçu, A. and Pulatsü, S. 2008. Phosphorus fractions in sediment profiles of the eutrophic Lake Mogan, Turkey. Fresenius Environmental Bulletin, 17, 2, 164-172.

Topçu, A. and Pulatsü, S. 2017. Evaluation of some management strategies in eutrophic Mogan Lake, Turkey: phosphorus mobility in the sediment-water interface. Applied Ecology and Environmental Research,15, (4), 705-717.

Topçu, A. Ulusoy, U., Pulatsü, S. 2018. Determination of sediment phosphate sorption characteristics in shallow Mogan Lake, Turkey. Applied Ecology and Environmental Research, 16, 5, 5971-5985.

Wang, X. Y. and Feng, J. 2007. Assessment of the effectiveness of environmental dredging boin South Lake, China. Environ. Manage., 40, 314-322.

Welch, E., B. and Jacoby, J., M. 2004. Pollutant Effects in Freshwater. Applied Limnology Third edition. Spon Press London and New York.

Xu, F.L., Tao, S., Dawson, R.W., Xu, Z, R. 2003. The distributions and effects of nutrients in the sediments of a shallow Chinese Lake. Hydrobiologia, 429, 85-93.

Yılgör, S., Küçüksezgin, F. ve Özel, E. 2012. Assessment of metal concentrations in sediments from lake Bafa (Western Anatolia): an index analysis approach. Bull Environ. Contam. Toxicol., 89, 512-518.

Zhang, S., Zhou, Q., Xu, D., Lin, J., Cheng, S., Wu, Z. 2010. Effects of sediment dredging on water quality and zooplankton community structure in a shallow of eutrophic lake. Journal of Environmental Sciences, 22, (2), 218-224.

Zhang, Z. L. Y. Zhang, W. Zhang, Y. Sun, C., Marhaba, T. 2015. Phosphorus, organic matter and nitrogen distribution characteristics of the surface sediments in Nansi Lake, China. Environ. Earth, 73, 5669-5675. 